\title{
Nutritional Status of Young Children with Inherited Blood Disorders in Western Kenya
}

\author{
Becky L. Tsang, Kevin M. Sullivan, Laird J. Ruth, Thomas N. Williams, and Parminder S. Suchdev* \\ Hubert Department of Global Health, Rollins School of Public Health and Department of Pediatrics, School of Medicine, Emory University, \\ Atlanta, Georgia; Nutrition Branch, Centers for Disease Control and Prevention, Atlanta, Georgia; Centre for Geographic Medicine Research-Coast, \\ Kenya Medical Research Institute, Kilifi, Kenya; Nuffield Department of Clinical Medicine, Oxford, United Kingdom
}

\begin{abstract}
To determine the association between a range of inherited blood disorders and indicators of poor nutrition, we analyzed data from a population-based, cross-sectional survey of 882 children 6-35 months of age in western Kenya. Of children with valid measurements, $71.7 \%$ were anemic (hemoglobin $<11 \mathrm{~g} / \mathrm{dL}$ ), $19.1 \%$ had ferritin levels $<12 \mu \mathrm{g} / \mathrm{L}$, and $30.9 \%$ had retinol binding protein (RBP) levels $<0.7 \mu \mathrm{mol} / \mathrm{L}$. Unadjusted analyses showed that compared with normal children, homozygous $\alpha^{+}$thalassemia individuals had a higher prevalence of anemia $(82.3 \%$ versus $66.8 \%, P=0.001)$, but a lower prevalence of low RBP $(20.5 \%$ versus $31.4 \%, P=0.024)$. In multivariable analysis, homozygous $\alpha^{+}$-thalassemia remained associated with anemia (adjusted odds ratio $[\mathrm{aOR}]=1.8, P=0.004)$ but not with low $\mathrm{RBP}(\mathrm{aOR}=0.6, P=0.065)$. Among young Kenyan children, $\alpha^{+}$-thalassemia is associated with anemia, whereas G6PD deficiency, haptoglobin 2-2, and $\mathrm{HbS}$ are not; none of these blood disorders are associated with iron deficiency, vitamin A deficiency, or poor growth.
\end{abstract}

\section{INTRODUCTION}

A high percentage of young children in Kenya have inherited blood disorders. Among the most common in this region are $\alpha^{+}$-thalassemia, sickle cell hemoglobin (HbS), glucose-6-phosphate dehydrogenase (G6PD) deficiency, and haptoglobin $(H p)$ 2-2. A high prevalence of all of these disorders have been shown previously in Kenya and elsewhere in subSaharan Africa, with heterozygous $\alpha^{+}$-thalassemia $(-\alpha / \alpha \alpha)$ and homozygous $(-\alpha /-\alpha) \alpha^{+}$-thalassemia estimated at $39 \%$ and $15 \%$, respectively, in coastal Kilifi, ${ }^{1}$ sickle cell trait (HbAS) prevalence estimated at 15-28\%, 2,3 G6PD deficiency estimated as high as $20 \%,{ }^{4}$ and $H p 2-2$ estimated as high as $25 \% ., 6$

All four blood disorders are associated with adverse health outcomes with varying severity and potential effect on nutrition status. Individuals with $\alpha^{+}$-thalassemia are largely asymptomatic, but experience chronic mild anemia. ${ }^{7} \mathrm{HbAS}$ is generally regarded as a benign condition, whereas sickle cell anemia (HbSS) is associated with chronic ill health and reduced life expectancy. ${ }^{8}$ Individuals with G6PD deficiency are more susceptible to hemolytic anemia triggered by certain drugs or foods. ${ }^{4}$ Inheritance of the $H p$ 2-2 genotype is not a blood disorder per se, but because the protein is active in iron metabolism, it may have a role in anemia., 9,10

The relationships between these four blood disorders and risk for anemia and malaria are multifaceted and have the potential to confound the interpretation of nutrition indicator outcomes if not taken into consideration. On one hand they may modify the risk of anemia and chronic malnutrition through reduced risk of severe malaria; ${ }^{11,12,13}$ on the other hand some inherited blood disorders (including $\alpha^{+}$-thalassemia and HbSS) can have a negative impact on hemoglobin concentration and subsequent growth. ${ }^{11,14}$ For example, studies have linked HbSS with growth retardation and an increase in macronutrient requirements, ${ }^{15,16}$ whereas the prevalence of stunting was reported to be lower among young HbAS children who experienced malaria episodes in Ghana than among HbAA children. ${ }^{13}$ Despite the potential for direct and indirect effects of anemia and malaria infection on growth and nutri-

*Address correspondence to Parminder S. Suchdev, Nutrition Branch, Centers for Disease Control and Prevention, 4770 Buford Hwy NE, MS-F77, Atlanta, GA 30341. E-mail: psuchdev@cdc.gov tion indicators, the relationships between inherited blood disorders and the overall nutritional status of young children are not well known. The confounding effects of inherited blood disorders are rarely considered in studies of nutrition in areas where inherited blood disorders are widespread.

Considering the high prevalence of blood disorders in subSaharan Africa, information about the relationship between them and children's risk for anemia, iron deficiency, vitamin A deficiency (VAD), and poor growth (stunting, underweight, wasting) can be useful for interpreting the results of nutrition surveys and monitoring the results of nutrition interventions.

Our purpose in this study was to investigate the relationship between each of four inherited blood disorders (Hp 2-2, G6PD deficiency, $\mathrm{HbAS} / \mathrm{HbSS}$, and the $\alpha^{+}$-thalassemia genotypes $[-\alpha / \alpha \alpha,-\alpha /-\alpha])$ and the prevalence of six conditions associated with poor nutrition (anemia, iron deficiency, VAD, stunting, wasting, and underweight) among preschool children in western Kenya.

\section{METHODS}

Study setting and design. We used data from a populationbased, cross-sectional survey of children who participated in the Nyando Integrated Child Health and Education Project (NICHE), a cluster randomized trial that evaluated the effectiveness of the promotion and sale of health products, including micronutrient powders, in 60 study villages during 2007-2010. A complete description of NICHE, including the study sampling methodology and results, are provided elsewhere. ${ }^{17-20}$

In brief, the survey was conducted in rural Nyando Division in Nyanza Province, western Kenya, where the population is of the Luo ethno-linguistic group and where the main occupation is subsistence farming; previously collected data from the NICHE project indicated a high rate of morbidity from malaria and poor nutrition among residents of this area. ${ }^{20}$ In 2007, researchers used the 1999 Nyando District census as a reference to select 30 intervention villages and 30 comparison villages for participation in the survey, with the probability of a village's selection proportional to its size. An updated household census was conducted before the August 2010 survey, and 19 compounds per village were randomly selected. All children 6-35 months of age from each compound were eligible for inclusion in the survey. Of 1,079 age-eligible 
60 villages in Nyando Division

1,140 households randomly selected

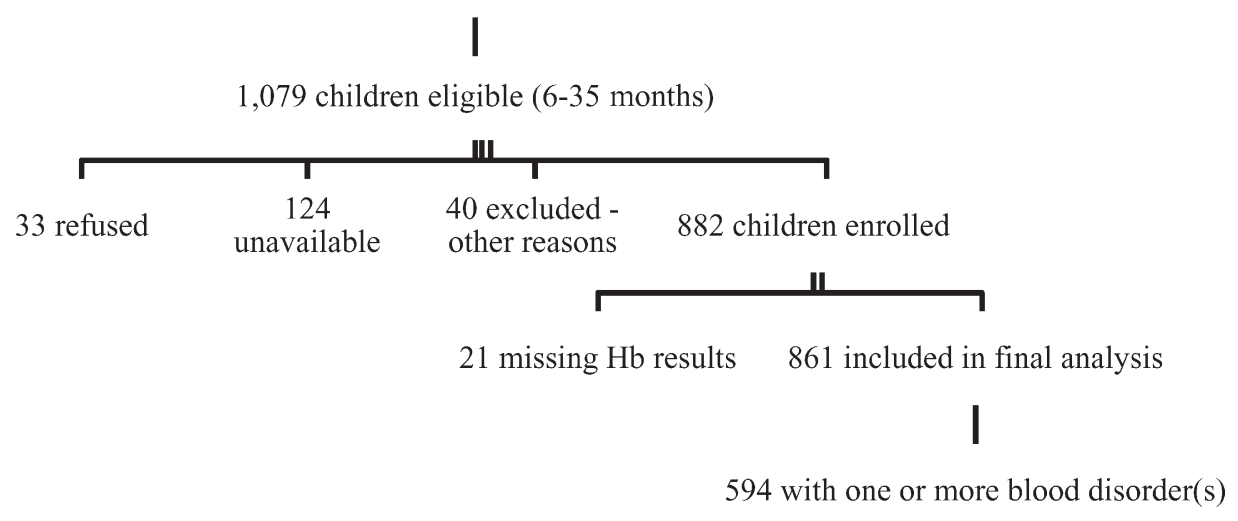

FIGURE 1. Selection of survey participants in Nyando Division, Kenya.

children, we included 861 in our analyses of survey data (Figure 1); however, because of inadequate blood samples from some children, we did not include all 861 in all analyses. Field staff used birth certificates or immunization records to verify the ages of all children in the survey.

Assessment of children's nutritional status, hemoglobin genotype, and socioeconomic status. Field workers administered a questionnaire to a parent or other primary caretaker of participating children to collect information on the children's age, sex, illness status, and use of micronutrient supplementation. The questionnaire was written in English, translated into the local Dholuo language, and back-translated into English to verify the accuracy of the original translation. Caretakers were asked to report whether children had experienced diarrhea, respiratory disease, or fever within the preceding 24 hours, and clinical malaria was diagnosed on the basis of a positive malaria blood smear in conjunction with a report of fever in the preceding 24 hours. The survey also collected data on multiple indicators of socioeconomic status (SES), including maternal education, household assets, and infrastructure.

Trained anthropometrists measured the recumbent length of children $<24$ months of age and the standing height of those $\geq 24$ months of age to the nearest $0.1 \mathrm{~cm}$ using a wooden measuring board (Irwin Shorr Productions, Olney, MD) and measured children's weight to the nearest $0.1 \mathrm{~kg}$ using a digital scale (Seca Corp., Hanover, MD). We defined stunting, underweight, and wasting as, respectively, a height-for-age $z$-score (HAZ), a weight-for-age $z$-score (WAZ), and a weight-for-height $z$-score (WHZ) less than two standard deviations below the mean values for these scores based on international growth standard data. ${ }^{21}$

Capillary blood was used for all hematological analyses. After wiping the first drop of blood, field workers measured the hemoglobin $(\mathrm{Hb})$ concentration in the second drop using a HemoCue B-Hemoglobin device (Ängelholm, Sweden), collected $400-500 \mu \mathrm{L}$ of blood in heparinized microcontainers, and made Giemsa-stained thick blood films. Microcontainers of collected blood were stored in cold boxes during the day until centrifugation each evening.
Anemia was defined as an $\mathrm{Hb}$ concentration $<11.0 \mathrm{~g} / \mathrm{dL} ;{ }^{22}$ because all study villages were at elevations below 1,000 m, we did not apply an altitude correction. Collected blood samples were analyzed at the Kenyan Medical Research Institute (KEMRI)/Centers for Disease Control and Prevention (CDC) laboratory in Kisian, Kenya to determine whether malaria parasitemia were present and, if so, in what quantity. Children with severe anemia ( $\mathrm{Hb}$ levels $<7.0 \mathrm{~g} / \mathrm{dL}$ ) or clinically diagnosed malaria were referred to the nearest hospital or clinic for follow-up. Ferritin, C-reactive protein (CRP), transferrin receptor (TfR), $\alpha$-1-acid glycoprotein (AGP), and retinol binding protein (RBP) were analyzed using a sandwich enzyme-linked immunosorbent assay (ELISA) technique (VitA-Iron Laboratory, Germany). ${ }^{23}$ Low ferritin was defined as a plasma ferritin concentration $<12 \mu \mathrm{g} / \mathrm{L},{ }^{24,25}$ and iron deficiency was defined as low ferritin in the absence of inflammation (a CRP level $\leq 5 \mathrm{mg} / \mathrm{L}$ and an AGP level $\leq 1 \mathrm{~g} / \mathrm{L}$ ). ${ }^{26}$ Although TfR data were collected, we did not include it in this analysis because of the potential effect of malaria, inflammation, and hemoglobinopathies on TfR levels. ${ }^{27} \mathrm{We}$ defined low RBP as $<0.7 \mu \mathrm{mol} / \mathrm{L}^{28}$ and VAD as low RBP with no inflammation.

$\beta$-globin genotyping for the $H b A$ and $H b S$ alleles and the 3.7-kilobase $\alpha$-globin chain deletion (the most common African form of $\alpha^{+}$-thalassemia) and the Hp genotypes were determined by polymerase chain reaction (PCR) as described in detail previously. ${ }^{10,29-31}$ On the basis of results from recent phenotypic studies (Shivang Shah, unpublished data), we classified males as G6PD-deficient if they were hemizygous for the $\mathrm{G} \mathrm{PD}^{\mathrm{A}-}$ allele and females as G6PD-deficient if they were either homozygous for the G6PD ${ }^{\mathrm{A}-}$ allele or heterozygous for both the G6PD ${ }^{\mathrm{A}-}$ and G6PD ${ }^{\mathrm{A}}$ alleles. ${ }^{29,32}$ All genetic analyses were conducted at the KEMRI-Wellcome Trust laboratory in Kilifi, Kenya; details of all analyses are available elsewhere. ${ }^{17,30,31}$

Iron supplementation and Sprinkles (a micronutrient powder) use were also assessed in the survey. The Sprinkles formulation used in this area included 14 micronutrients, including $12.5 \mathrm{mg}$ of iron as microencapsulated ferrous fumarate and $375 \mu \mathrm{g}$ of vitamin A. ${ }^{33}$ SES was categorized in 
quintiles to relative poverty using a principal components analysis (PCA) wealth index developed by the World Bank. ${ }^{34}$

Data synthesis. In our analyses, we categorized children into two age groups: 6-23 months and 24-35 months to capture those within the critical nutrition period of $<24$ months compared with those 24 months and over. ${ }^{35}$ The Hb, ferritin, and RBP levels were dichotomized using the cut-off points defined previously because the primary objective was to identify whether nutritional status at internationally accepted definitions varied by blood disorder. Because only 30 children were classified as wasted, we did not include wasting as a covariate in logistic regression.

Statistical analysis. We used the Rao-Scott $\chi^{2}$ test $^{36}$ to identify crude associations between the blood disorders (primary exposure) and other variables. We then used logistic regression analysis to assess the relationship between each blood disorder and any nutrition outcome (anemia, low ferritin, low RBP, stunting, wasting, and underweight) shown to be statistically significant $\left(\chi^{2} P<0.05\right)$. The HbAA children served as the reference for those with HbAS, normal $(\alpha \alpha / \alpha \alpha)$ genotype or heterozygote $(-\alpha / \alpha \alpha)$ children for $\alpha^{+}$-thalassemia homozygote children $(-\alpha /-\alpha)$; children with normal G6PD levels for those with G6PD deficiency, and children with the Hp 1-1/Hp 2-1 genotype served as the reference group in analyses for $\mathrm{Hp} 2$ 2-2. Because only 14 children carried the HbSS genotype, we did not include these children in the logistic regression analysis.

In multivariable models, acute and chronic inflammation were accounted for by controlling for both CRP and AGP in the adjusted model. ${ }^{26} \mathrm{We}$ also assessed for interaction and confounding of covariates identified in previous studies, including male sex, low SES (defined as the bottom three PCA quintiles), illness (diarrhea, respiratory illness, or fever) within the preceding 24 hours, child-feeding practices in the preceding 24 hours (breastfeeding, tea consumption, iron supplementation, use of Sprinkles, dirt/earth consumption [a form of pica behavior]), inflammation (elevated CRP and/or AGP), and malaria status. To account for co-inheritance of blood disorders and co-existing health conditions, we also included nutrition outcomes and blood disorders as covariates in initial models. Blood disorders were retained in final models regardless of $P$ value.

We included covariates in our full logistic regression model if results of our bivariate analysis indicated there was a significant association with a blood disorder $(P<0.05)$, if the interaction between the primary exposure and covariate was significant $(P<0.05)$, or if they changed the odds ratio $(\mathrm{OR})$ for the relationship between the primary exposure and the covariate by more than $10 \%$. We conducted backward regression first for any interaction terms and then by removing variables that were not confounders or independent predictors of the outcome. At each step, we monitored the OR for the relationship between the primary exposure and the covariate to ensure that removal of a covariate did not result in confounding. However, we kept age, sex, and all other blood disorders in the model as potential confounding covariates regardless of the $P$ value for their relationship with a blood disorder of interest. We used the same process for all significant associations between blood disorders and indicators of poor nutrition. We defined collinearity between covariates as condition indices $(\mathrm{CI})>30$ using a SAS colinearity macro ${ }^{37}$ in the final models. Final models included all remaining signifi- cant two-way interactions, statistically significant independent variables, and confounding variables as defined above.

Data were analyzed using SAS version 9.3 (SAS Institute Inc., Cary, NC) taking into account the complex survey design of 60 primary sampling units (villages) by using PROC SURVEYFREQ and PROC SURVEYLOGISTIC. We considered results to be statistically significant if two-sided $P$ values were $<0.05$.

Ethical considerations. The Scientific Steering Committee and the Ethical Review Committee of KEMRI in Nairobi and the CDC Institutional Review Board approved all study protocols.

\section{RESULTS}

We classified $29.8 \%$ of children surveyed as stunted, $12.1 \%$ as underweight, $3.5 \%$ as wasted, $19.1 \%$ as having low ferritin levels, and $30.9 \%$ as having low RBP levels (Table 1). We classified $59.4 \%$ as having one or more of the following genotypes or conditions: $H p$ 2-2, G6PD deficiency, $\alpha^{+}$-thalassemia,

TABLE 1

Characteristics and health indicators of children aged 6-35 months in western Kenya, 2010*

\begin{tabular}{|c|c|c|}
\hline Total sample size $=861$ & $\mathrm{n} / N$ & $\%$ \\
\hline Sex, female & $427 / 861$ & 49.6 \\
\hline Age, 6-23 months & $463 / 861$ & 53.8 \\
\hline Child slept under bed net previous night & $777 / 837$ & 92.8 \\
\hline \multicolumn{3}{|l|}{ Inherited blood disorders } \\
\hline G6PD deficiency & $56 / 829$ & 6.8 \\
\hline $\begin{array}{l}\text { Haptoglobin polymorphism, } H p 2-2 \\
\alpha^{+} \text {-Thalassemia }\end{array}$ & $164 / 805$ & 20.4 \\
\hline Heterozygotes $(\alpha \alpha /-\alpha)$ & $319 / 826$ & 38.6 \\
\hline Homozygotes $(-\alpha /-\alpha)$ & $79 / 826$ & 9.6 \\
\hline \multicolumn{3}{|l|}{ Sickle cell hemoglobin } \\
\hline Trait (HbAS) & $146 / 857$ & 17.0 \\
\hline SCA (HbSS) & $14 / 857$ & 1.6 \\
\hline \multicolumn{3}{|l|}{ Nutrition status } \\
\hline Anemia $(\mathrm{Hb}<11 \mathrm{~g} / \mathrm{dL})$ & $617 / 861$ & 71.7 \\
\hline Plasma ferritin $<12 \mu \mathrm{g} / \mathrm{L} \dagger$ & $162 / 850$ & 19.1 \\
\hline Iron deficiency $\$$ & $124 / 333$ & 37.2 \\
\hline Retinol binding protein $<0.7 \mu \mathrm{mol} / \mathrm{L} \dagger$ & $263 / 850$ & 30.9 \\
\hline Vitamin A deficiency $¥$ & $52 / 333$ & 15.6 \\
\hline \multicolumn{3}{|l|}{ Inflammation } \\
\hline C-reactive protein $>5.0 \mathrm{mg} / \mathrm{L}$ & $292 / 850$ & 34.4 \\
\hline$\alpha_{1}$-acid glycoprotein $>1.0 \mathrm{~g} / \mathrm{L}$ & $518 / 850$ & 60.9 \\
\hline $\begin{array}{l}\text { Any inflammation (AGP }>1.0 \mathrm{~g} / \mathrm{L} \text { or } \\
\text { CRP }>5.0 \mathrm{mg} / \mathrm{L})\end{array}$ & $528 / 861$ & 61.3 \\
\hline \multicolumn{3}{|l|}{ Anthropometry } \\
\hline Stunted $(\mathrm{HAZ}<-2.0)$ & $255 / 856$ & 29.8 \\
\hline Underweight (WAZ $<-2.0$ ) & $104 / 859$ & 12.1 \\
\hline Wasted $(\mathrm{WHZ}<-2.0)$ & $30 / 857$ & 3.5 \\
\hline \multicolumn{3}{|l|}{ Nutrition practices } \\
\hline Sprinkles (in last $24 \mathrm{hr}$ ) & $92 / 837$ & 11.0 \\
\hline Iron supplementation (in last $24 \mathrm{hr}$ ) & $58 / 839$ & 6.3 \\
\hline Tea consumption (in last $24 \mathrm{hr}$ ) & $692 / 832$ & 83.2 \\
\hline Breast-feeding (in last $24 \mathrm{hr}$ ) & $417 / 838$ & 49.8 \\
\hline Self-reported pica (in last $24 \mathrm{hr}$ ) & $382 / 800$ & 47.8 \\
\hline \multicolumn{3}{|l|}{ Illness } \\
\hline Clinical malaria & $124 / 857$ & 14.5 \\
\hline Diarrhea (in last $24 \mathrm{hr}$ ) & 203/836 & 24.3 \\
\hline Fever (in last $24 \mathrm{hr}$ ) & $349 / 829$ & 42.1 \\
\hline Respiratory (in last $24 \mathrm{hr}$ ) & $319 / 839$ & 38.0 \\
\hline
\end{tabular}


TABLE 2

Nutrition and anthropometry indicators of participant children by blood disorder in western Kenya, 2010* $\dagger$

\begin{tabular}{|c|c|c|c|c|c|c|}
\hline & $\begin{array}{c}\text { Anemia }(\mathrm{Hb}<11 \mathrm{~g} / \mathrm{dL}) \\
N=861\end{array}$ & $\begin{array}{c}\text { Ferritin }<12 \mu \mathrm{g} / \mathrm{L} \neq \\
\quad N=850\end{array}$ & $\begin{array}{c}\mathrm{RBP}<0.7 \mu \mathrm{mol} / \mathrm{L} \dot{+} \\
\quad N=850\end{array}$ & $\begin{array}{c}\text { Stunted }(\mathrm{HAZ}<-2), \% \\
\qquad N=856\end{array}$ & $\begin{array}{c}\text { Underweight (WAZ }<-2), \% \\
\qquad N=859\end{array}$ & $\begin{array}{c}\text { Wasted }(\text { WHZ }<-2), \% \\
\qquad N=857\end{array}$ \\
\hline \multicolumn{7}{|l|}{ G6PD deficiency, $N=829$} \\
\hline Normal & $551 / 773(71.3)$ & $148 / 766(19.3)$ & 238/766 (31.1) & $228 / 769(29.6)$ & 95/771 (12.3) & $29 / 770(3.8)$ \\
\hline Deficient & $40 / 56(71.4)$ & $9 / 56(16.1)$ & $14 / 56(25.0)$ & $21 / 56(37.5)$ & $8 / 56(14.3)$ & $1 / 56(1.8)$ \\
\hline$P$ value $($ ref $=$ normal $)$ & 0.980 & 0.546 & 0.323 & 0.148 & 0.670 & 0.455 \\
\hline \multicolumn{7}{|l|}{ Hp polymorphism, $N=858$} \\
\hline Hр 1-1 or $H p$ 2-1 & $457 / 641(71.3)$ & 118/633 (18.6) & $187 / 633(29.5)$ & $190 / 638(29.8)$ & 76/640 (11.9) & 23/639 (3.6) \\
\hline Hр 2-2 & $122 / 164(74.4)$ & 33/164 (20.1) & $59 / 164(36.0)$ & $49 / 163(30.1)$ & 21/163 (12.9) & $6 / 163(3.7)$ \\
\hline $\begin{array}{l}P \text { value }(\text { ref }=H p 1-1 \text { or } \\
\qquad H p 2-1)\end{array}$ & 0.411 & 0.686 & 0.088 & 0.940 & 0.689 & 0.951 \\
\hline \multicolumn{7}{|l|}{$\alpha^{+}$-Thalassemia, $N=826$} \\
\hline Normal $(\alpha \alpha / \alpha \alpha)$ & $286 / 428(66.8)$ & $80 / 427(18.7)$ & $134 / 427(31.4)$ & $131 / 426(30.8)$ & $56 / 428(13.1)$ & $17 / 427(4.0)$ \\
\hline Heterozygotes $(-\alpha / \alpha \alpha)$ & $241 / 319(75.6)$ & $60 / 313(19.2)$ & $104 / 313(33.2)$ & $93 / 318(29.2)$ & $34 / 319(10.7)$ & $10 / 319(3.1)$ \\
\hline$P$ value $(\operatorname{ref}=\alpha \alpha / \alpha \alpha)$ & 0.014 & 0.894 & 0.600 & 0.677 & 0.340 & 0.595 \\
\hline Homozygotes $(-\alpha /-\alpha)$ & $65 / 79(82.3)$ & $16 / 78(20.5)$ & $16 / 78(20.5)$ & $22 / 78(28.2)$ & $12 / 77(15.6)$ & 3/77 (3.9) \\
\hline$P$ value $($ ref $=\alpha \alpha / \alpha \alpha)$ & 0.001 & 0.717 & 0.024 & 0.668 & 0.550 & 0.968 \\
\hline \multicolumn{7}{|l|}{$\mathrm{HbS}, N=857$} \\
\hline Normal (HbAA) & $504 / 697(72.3)$ & 127/691 (18.4) & 215/691 (31.1) & $200 / 693(28.9)$ & $81 / 695(11.7)$ & 26/694 (3.7) \\
\hline Trait (HbAS) & $101 / 146(69.2)$ & $34 / 144(23.6)$ & $46 / 144(31.9)$ & $52 / 146(35.6)$ & $22 / 146(15.1)$ & $4 / 146(2.7)$ \\
\hline$P$ value $($ ref $=$ HbAA $)$ & 0.466 & 0.154 & 0.847 & 0.086 & 0.169 & 0.475 \\
\hline SCA (HbSS) & $10 / 14(71.4)$ & $1 / 14(7.14)$ & $1 / 14(7.1)$ & $3 / 14(21.4)$ & $1 / 14(7.14)$ & $0 / 14(0)$ \\
\hline$P$ value $($ ref $=\mathrm{HbAA})$ & 0.945 & 0.273 & 0.056 & 0.504 & 0.584 & - \\
\hline
\end{tabular}

or $\mathrm{HbAS} / \mathrm{HbSS}$. In the overall population, $38.6 \%$ were $\alpha^{+}$thalassemia heterozygotes, $9.6 \% \alpha^{+}$-thalassemia homozygotes, 20.4\% had Hp 2-2, 17.0\% had HbAS, 1.6\% had HbSS, and $6.8 \%$ had G6PD deficiency; the prevalence of these genotypes and conditions did not differ significantly by sex (data not shown).

Anemia prevalence did not differ significantly by Hp subtype, HbS genotype, or G6PD deficiency status (Table 2). However, the prevalence of anemia did differ significantly by $\alpha^{+}$-thalassemia strata (overall trend $P=0.003$, not shown), with the prevalence being significantly higher among homozygotes compared with heterozygotes $(P=0.014)$ or the normal genotype $(P=0.001)$. Both heterozygotes and homozygotes were more likely to have anemia than were those with normal genotype (crude ORs = 1.53 and 2.31, respectively, not shown).

We found no significant bivariate association between low ferritin levels and any of the blood disorders investigated. The prevalence of low RBP was significantly lower among children with homozygous $\alpha^{+}$-thalassemia $(P=0.024)$ compared with those with normal genotype; however, the prevalence of low RBP did not differ significantly between $\alpha^{+}$-thalassemia heterozygous children and those with normal genotype $(P=$ 0.600). There was no significant relationship between low RBP status and any of the other blood disorders. After we removed children with any inflammation $(N=517 ; 60.8 \%$ of the study population) from our analyses for VAD and iron deficiency, iron deficiency was not associated with any disorders and VAD was associated only with the heterozygous $\alpha^{+}$thalassemia genotype ( $P=0.034$, not shown). Given the high percentage of children excluded because of inflammation, we did not conduct a logistic regression analysis of the relationship between VAD $(\mathrm{RBP}<0.7 \mu \mathrm{mol} / \mathrm{L}$ and no inflammation $)$ and $\alpha^{+}$-thalassemia.

Inflammation was not significantly associated with any of the inherited blood disorders; elevated CRP varied from 21.4-37.2\%, whereas elevated AGP varied from 53.6-64.3\% among the disorders (not shown). None of the inherited blood disorders were associated with the prevalence of stunting, wasting, or underweight.

Relationship between homozygous $\alpha^{+}$-thalassemia $(-\alpha /-\alpha)$ and low RBP. After adjusting for significant covariates, multivariate logistic regression results showed no significant relationship between homozygosity for $\alpha^{+}$-thalassemia and low RBP (aOR $=0.61, P=0.065 ; 95 \% \mathrm{CI}=0.36-1.03$ ) but did show low RBP to be associated with a greater prevalence of being underweight, having inflammation, and testing positive for malaria (Table 3 ). We retained age group in the regression model to control for any confounding as a result of survival bias, and we kept HbAS, Hp 2-2 and G6PD deficiency in the model as potential confounders because of co-inheritance of blood disorders. We found no evidence of significant colinearity among the independent variables.

Relationship between $\alpha^{+}$-thalassemia $(-\alpha / \alpha \alpha,-\alpha /-\alpha)$ and anemia. After adjusting for significant covariates, $\alpha^{+}$thalassemia was still positively associated with anemia $(P=$ 0.004) (Table 4); children with $\alpha^{+}$-thalassemia were significantly more likely to have anemia than those without $(\mathrm{aOR}=$ $1.78 ; 95 \% \mathrm{CI}=1.20-2.62)$. Other variables in the adjusted model associated with anemia were young age (6-23 months), low SES, male sex, low ferritin concentration, inflammation, and a positive malaria smear. Of these, a positive malaria smear $(\mathrm{aOR}=6.81,95 \% \mathrm{CI}=4.26-10.89)$, a low ferritin concentration $(\mathrm{aOR}=4.43,95 \% \mathrm{CI}=2.67-7.32)$, and inflammation $(\mathrm{aOR}=3.24,95 \% \mathrm{CI}=2.04-5.14)$ had the strongest associations with anemia. We kept HbAS, $H p$ 2-2, and G6PD deficiency in the model as potential confounders and found no evidence of significant colinearity among the covariates.

\section{DISCUSSION}

Despite a high prevalence of both malnutrition and inherited blood disorders in this population, we found no significant 
TABLE 3

Factors associated with low RBP among young children aged 6-35 months in western Kenya, 2010* $(N=756)$

\begin{tabular}{|c|c|c|c|}
\hline \multirow[b]{2}{*}{ Variable } & \multirow[b]{2}{*}{ Unadjusted OR } & \multicolumn{2}{|c|}{ Adjusted model } \\
\hline & & OR $(95 \% \mathrm{CI})$ & $P$ \\
\hline \multicolumn{4}{|l|}{ Primary exposure } \\
\hline$\alpha^{+}$-Thalassemia: $-\alpha /-\alpha(\operatorname{ref}=\alpha \alpha / \alpha \alpha$ or $-\alpha / \alpha \alpha)$ & $0.54 \dagger$ & $0.61(0.36-1.03)$ & 0.065 \\
\hline \multicolumn{4}{|l|}{ Child demographics and characteristics } \\
\hline Age $6-23$ months (ref $=24-35$ months $)$ & 0.98 & $1.12(0.79-1.70)$ & 0.451 \\
\hline Underweight $($ ref $=$ WAZ $\geq-2)$ & $2.30 \dagger$ & $1.96(1.15-3.34)$ & 0.014 \\
\hline \multicolumn{4}{|l|}{ Morbidity and infection } \\
\hline Inflammation $($ ref $=$ normal CRP and AGP $)$ & $4.97 \dagger$ & $3.33(2.14-5.18)$ & $<0.001$ \\
\hline Positive malaria smear (ref $=$ no malaria $)$ & $3.90 \dagger$ & $2.72(1.91-3.87)$ & $<0.001$ \\
\hline \multicolumn{4}{|l|}{ Blood disorders } \\
\hline G6PD deficiency (ref = normal) & 0.74 & $0.84(0.41-1.69)$ & 0.615 \\
\hline $\mathrm{HbAS}(\mathrm{ref}=\mathrm{HbAA})$ & 0.86 & $1.05(0.66-1.69)$ & 0.829 \\
\hline$H p$ 2-2 $(\mathrm{ref}=H p$ 1-1 and $H p$ 2-1) & 1.34 & $1.41(0.97-2.05)$ & 0.074 \\
\hline
\end{tabular}

associations between the blood disorders and conditions indicative of poor nutrition, except for a positive association between $\alpha^{+}$-thalassemia and anemia, which has been found previously Kenya, Nigeria, and Cambodia population. ${ }^{1,14,38}$ Thus, our results suggest that $\alpha^{+}$-thalassemia should be considered when evaluating anemia etiology and the impact of anemia interventions. However, there may be limited value of the other measured blood disorders (G6PD deficiency, $H p$ 2-2, and HbAS) in interpreting cross-sectional nutrition surveys.

Although anemia prevalence differed by $\alpha^{+}$-thalassemia genotype, the prevalence of low ferritin levels did not. Our finding is consistent with a previous study among children on the coast of Kenya. ${ }^{39}$ It is well known that anemia prevalence in children with $\alpha^{+}$-thalassemia is associated with the disorder itself or another mechanism associated with the disorder, rather than with $\alpha^{+}$-thalassemia's relationship to iron metabolism. . $^{70}$

The relationship between $\alpha^{+}$-thalassemia and anemia is especially important in locations such as western Kenya where malaria is endemic and the prevalence of $\alpha^{+}$-thalassemia (48.2\% overall) is high. Awareness of the underlying prevalence of blood disorders in a population may help program officials better interpret the impact of interventions to prevent and treat anemia. Impact evaluations of anemia prevention or treatment programs may not be a true reflection of program success because anemia attributable to $\alpha^{+}$-thalassemia will not be corrected. Though systematic screening for $\alpha^{+}$thalassemia may be unrealistic in regions with limited resources, partial population sampling or understanding of the distribution of $\alpha^{+}$-thalassemia are potential tools that could be considered during monitoring and evaluation of anemia control programs.

We found a relatively high prevalence of low RBP and VAD across all blood disorder subgroups. ${ }^{41} \mathrm{We}$ also found that low RBP status was associated with being underweight, having a positive malaria smear, and having elevated levels of inflammatory markers. Clinical trial results have shown that vitamin A supplementation can decrease the parasite load, ${ }^{42}$ but it is unclear if vitamin A supplementation has any

TABLE 4

Factors associated with anemia among young children aged 6-35 months in western Kenya, 2010* $(N=739)$

\begin{tabular}{|c|c|c|c|}
\hline \multirow[b]{2}{*}{ Variable } & \multirow[b]{2}{*}{ Unadjusted OR } & \multicolumn{2}{|c|}{ Adjusted model } \\
\hline & & OR $(95 \% \mathrm{CI})$ & $P$ \\
\hline \multicolumn{4}{|l|}{ Primary exposure } \\
\hline$\alpha^{+}$-Thalassemia $-\alpha / \alpha \alpha$ or $-\alpha /-\alpha($ ref $=\alpha \alpha / \alpha \alpha)$ & $1.65 \dagger$ & $1.78(1.20-2.62)$ & 0.004 \\
\hline \multicolumn{4}{|l|}{ Child demographics and characteristics } \\
\hline Age $6-23$ months (ref $=24-35$ months) & $1.48 \dagger$ & $1.35(0.91-2.01)$ & 0.140 \\
\hline Breastfeeding in the last 24 hours & $1.54 \dagger$ & $1.38(0.94-2.05)$ & 0.103 \\
\hline SES quintile $1-3($ ref $=$ quintile $4-5)$ & $1.44 \dagger$ & $1.52(1.06-2.19)$ & 0.024 \\
\hline Male (ref = female $)$ & $1.51 \dagger$ & $1.66(1.06-2.59)$ & 0.026 \\
\hline Underweight ( $\mathrm{ref}=\mathrm{WAZ} \geq-2)$ & $2.20 \dagger$ & $1.85(1.02-3.34)$ & 0.043 \\
\hline \multicolumn{4}{|l|}{ Morbidity and infection } \\
\hline Low iron $($ ref $=$ ferritin $\geq 12 \mu \mathrm{g} / \mathrm{L})$ & $1.79 \dagger$ & $4.43(2.67-7.32)$ & $<0.001$ \\
\hline Inflammation $(\mathrm{ref}=$ normal CRP \& AGP) & $3.43 \dagger$ & $3.24(2.04-5.14)$ & $<0.001$ \\
\hline Positive malaria smear $($ ref $=$ no malaria $)$ & $5.79 \dagger$ & $6.81(4.26-10.89)$ & $<0.001$ \\
\hline \multicolumn{4}{|l|}{ Blood disorders } \\
\hline G6PD deficiency $($ ref = normal) & 1.01 & $1.01(0.45-2.31)$ & 0.906 \\
\hline $\mathrm{HbAS}(\mathrm{ref}=\mathrm{HbAA})$ & 0.47 & $0.69(0.41-1.16)$ & 0.165 \\
\hline$H p 2-2($ ref $=H p 1-1$ or $H p 2-1)$ & 1.23 & $0.97(0.63-1.50)$ & 0.905 \\
\hline
\end{tabular}


effect on malarial infection in an endemic area such as Nyando. ${ }^{43}$

Although our unadjusted results showed an inverse association between homozygous $\alpha^{+}$-thalassemia and low RBP, this relationship was no longer significant after we controlled for other variables. However, our fully adjusted results were close to statistical significance, and our nonsignificant finding may be a result of the low number of children in our study population who had homozygous $\alpha^{+}$-thalassemia. If homozygosity for $\alpha^{+}$-thalassemia and RBP levels is truly associated, studies of potential mechanisms behind this association and studies of the relationship between $\alpha^{+}$-thalassemia and VAD in a population with a lower prevalence of inflammation may be warranted.

Our finding that $\mathrm{HbAS}$ was not associated with stunting or anemia was inconsistent with previous findings. ${ }^{44,45}$ However, there is evidence that biological interactions among co-inherited hemoglobinopathies ${ }^{46}$ may have limited our ability to detect any such reduction in prevalence associated with HbAS. Additionally, because of low sample sizes, we were unable to assess nutritional status with HbSS, which has been shown to be associated with stunting and micronutrient deficiencies.

Our findings also did not indicate a relationship between nutritional outcomes and either G6PD deficiency or Hp polymorphism, which was unexpected given that both blood disorders have previously been associated with malaria., ${ }^{5,47}$ Theoretically, people at increased malarial risk from $\mathrm{Hp}$ 2-2 and exposure to hemolytic events from G6PD deficiency would be at higher risk for chronic anemia, with expected consequences on growth indicators.

It is important to note that in low-resource environments where the prevalence of disease is high throughout the population, any additional disease attributable to inherited blood disorders may be difficult to detect. In addition, as a crosssectional study, survival bias is a potential confounding factor in the relationship between disease prevalence and either HbSS or G6PD deficiency. In our study cohort, HbSS children were, on average, 8 months younger than those with other genotypes, suggesting that older HbSS children may not have survived. Severe symptoms of G6PD deficiency include neonatal complications such as jaundice, which may lead to death if not treated. As such, we were not able to assess the relationship between nutrition and blood disorders among children with severe forms of these diseases.

In communities with a higher SES distribution and lower rates of child morbidity and mortality attributable to poor sanitation and infectious diseases, child survival will likely be more common. As health outcomes improve in populations with a high prevalence of inherited blood disorders and more children reach adulthood, it will be even more important to understand how inherited blood disorders may be associated with poor nutrition.

Study strengths and limitations. A strength of this study was our analysis of data based on the measurement of multiple nutrition biomarkers and the genotyping of multiple blood disorders. However, because of the cross-sectional survey design, any associations between blood disorders and conditions related to malnutrition do not necessarily indicate a causal relationship. In addition, the use of OR in a crosssectional study overstates the prevalence ratio because the outcomes studied in this analysis are common.
Other study limitations included potential information bias from self-reported household data, analysis of data from a relatively small area of Kenya (Nyando Division), which may not be representative of the country as a whole, and inability to assess to what magnitude blood disorders change hematologic nutrition indicators. In addition, the survey tool did not collect data on other potential confounding factors such as helminth or roundworm parasite infections, vitamin A supplementation, and recent treatment with antimalarial medication, which limited analyses.

\section{CONCLUSION}

Our findings showed that in western Kenya, an area with a high prevalence of childhood malnutrition, inherited blood disorders are not associated with most indicators of poor nutritional status. There may be limited value in assessing blood disorders for measuring certain nutritional outcomes, such as growth. The only significant association we found was between $\alpha^{+}$thalassemia and anemia. Regional anemia prevalence estimates should take this association into consideration when interpreting anemia etiologies and when recommending nutritional interventions such as iron supplementation.

Received August 27, 2013. Accepted for publication January 23, 2014. Published online March 17, 2014.

Acknowledgments: We are grateful for the assistance given by participants, the staff of the Safe Water and AIDS Project, KEMRI, the CDC offices based in Kenya, and the Nyando Integrated Child Health and Education Project study team, and to Juergen Erhardt for performing the micronutrient analyses for our study. We thank the staff of the Human Genetics Laboratory at the KEMRI Centre for Geographic Research-Coast, Kilifi, including Alex Macharia, Emily Nyatichi, Metrine Tendwa, Johnstone Mkale, and Adan Mohamed for genotyping collected blood samples, and Gideon Nyutu and Ruth Mwarabu for database support.

Financial support: This work was supported by the U. S. Centers for Disease Control and Prevention (CDC) through a cooperative agreement between $\mathrm{CDC}$ and the Kenya Medical Research Institute (KEMRI) and a senior fellowship from the Wellcome Trust, UK (091758).

Disclosure: This paper is published with the permission of the Director of KEMRI.

Disclaimer: The findings and conclusions in this report are those of the authors and do not necessarily represent the official position of the Centers for Disease Control and Prevention.

Authors' addresses: Becky L. Tsang, Prevention Research Branch, Centers for Disease Control and Prevention, Atlanta, GA, E-mail: woh3@cdc.gov. Kevin M. Sullivan, Hubert Department of Global Health, Rollins School of Public Health, Emory University, Atlanta, GA, E-mail: cdckms@sph.emory.edu. Laird J. Ruth and Parminder S. Suchdev, Nutrition Branch, Centers for Disease Control and Prevention, Atlanta, GA, E-mails: lruth@cdc.gov and dvo8@cdc.gov. Thomas N. Williams, Centre for Geographic Medicine ResearchCoast, Kenya Medical Research Institute, Kilifi, Kenya, E-mail: twilliams@kilifi.kemri-wellcome.org.

\section{REFERENCES}

1. Wambua S, Mwangi TW, Kortok M, Uyoga SM, Macharia AW, Mwacharo JK, Weatherall DJ, Snow RW, Marsh K, Williams TN, 2006. The effect of alpha+-thalassemia on the incidence of malaria and other diseases in children living on the coast of Kenya. PLoS Med 3: e158. 
2. Foy H, Kondi A, Timms GL, Brass W, Bushra F, 1954. The variability of sickle-cell rates in the tribes of Kenya and the southern Sudan. BMJ 1: 294-297.

3. Williams TN, Mwangi TW, Wambua S, Peto TE, Weatherall DJ, Gupta S, Recker M, Penman BS, Uyoga S, Macharia A, Mwacharo JK, Snow RW, Marsh K, 2005. Negative epistasis between the malaria-protective effects of alpha+-thalassemia and the sickle cell trait. Nat Genet 37: 1253-1257.

4. Beutler E, Duparc S, 2007. Glucose-6-phosphate dehydrogenase deficiency and antimalarial drug development. Am J Trop Med Hyg 77: 779-789.

5. Greene LS, 1993. G6PD deficiency as protection against falciparum malaria: an epidemiologic critique of population and experimental studies. Yearb Phys Anthropol 36: 153-178.

6. Atkinson SH, Mwangi TW, Uyoga SM, Ogada E, Macharia AW, Marsh K, Prentice AM, Williams TN, 2007. The haptoglobin 2-2 genotype is associated with a reduced incidence of Plasmodium falciparum malaria in children on the coast of Kenya. Clin Infect Dis 44: 802-809.

7. Williams TN, Maitland K, Ganczakowski M, Peto TE, Clegg JB, Weatherall DJ, Bowden DK, 1996. Red blood cell phenotypes in the alpha+ thalassemias from early childhood to maturity. Br J Haematol 95: 266-272.

8. Grosse SD, Odame I, Atrash HK, Amendah DD, Piel FB, Williams TN, 2011. Sickle cell disease in Africa: a neglected cause of early childhood mortality. Am J Prev Med 41: S398-S405.

9. Cox SE, Doherty C, Atkinson SH, Nweneka CV, Fulford AJ, Ghattas H, Rockett KA, Kwiatkowski DP, Prentice AM, 2007. Haplotype association between haptoglobin (Hp2) and Hp promoter SNP (A-61C) may explain previous controversy of haptoglobin and malaria protection. PLoS ONE 2: e362.

10. Atkinson SH, Rockett K, Sirugo G, Bejon PA, Fulford A, O'Connell MA, Bailey R, Kwiatkowski DP, Prentice AM, 2006. Seasonal childhood anemia in West Africa is associated with the haptoglobin 2-2 genotype. PLoS Med 3: e172.

11. Cox SE, Doherty CP, Atkinson SH, Nweneka CV, Fulford AJ, Sirugo G, Rockett KA, Kwiatkowski DP, Prentice AM, 2008. Haptoglobin genotype, anemia and malaria in Gambian children. Trop Med Int Health 13: 76-82.

12. Allen SJ, O'Donnell A, Alexander ND, Alpers MP, Peto TE, Clegg JB, Weatherall DJ, 1997. alpha+-Thalassemia protects children against disease caused by other infections as well as malaria. Proc Natl Acad Sci USA 94: 14736-14741.

13. Kreuels B, Ehrhardt S, Kreuzberg C, Adjei S, Kobbe R, Burchard GD, Ehmen C, Ayim M, Adjei O, May J, 2009. Sickle cell trait (HbAS) and stunting in children below two years of age in an area of high malaria transmission. Malar J 8: 16.

14. Mockenhaupt FP, Falusi AG, May J, Ademowo OG, Olumese PE, Meyer CG, Bienzle U, 1999. The contribution of alpha+-thalassemia to anemia in a Nigerian population exposed to intense malaria transmission. Trop Med Int Health 4: 302-307.

15. Gray NT, Bartlett JM, Kolasa KM, Marcuard SP, Holbrook CT, Horner RD, 1992. Nutritional status and dietary intake of children with sickle cell anemia. Am J Pediatr Hematol Oncol 14: 57-61.

16. Cox SE, Makani J, Fulford AJ, Komba AN, Soka D, Williams TN, Newton CR, Marsh K, Prentice AM, 2011. Nutritional status, hospitalization and mortality among patients with sickle cell anemia in Tanzania. Haematologica 96: 948-953.

17. Suchdev PS, Ruth LJ, Earley M, Macharia A, Williams TN, 2012. The burden and consequences of inherited blood disorders among young children in western Kenya. Matern Child Nutr 10: $135-144$.

18. Suchdev PS, Ruth LJ, Woodruff BA, Mbakaya C, Mandava U, Flores-Ayala R, Jefferds ME, Quick R, 2012. Selling Sprinkles micronutrient powder reduces anemia, iron deficiency, and vitamin A deficiency in young children in western Kenya: a cluster-randomized controlled trial. Am J Clin Nutr 95: 1223-1230.

19. Suchdev PS, Ruth L, Obure A, Were V, Ochieng C, Ogange L, Owuor M, Ngure F, Quick R, Juliao P, Jung C, Teates K, Cruz K, Jefferds ME, 2010. Monitoring the marketing, distribution, and use of Sprinkles micronutrient powders in rural western Kenya. Food Nutr Bull 31: S168-S178.
20. CDC, 2007. Baseline data from the Nyando Integrated Child Health and Education Project-Kenya, 2007. MMWR Morb Mortal Wkly Rep 56: 1109-1113.

21. World Health Organization, 2006. Child Growth Standards. Geneva: World Health Organization.

22. World Health Organization, 2001. Iron Deficiency Anemia: Assessment, Prevention, and Control. A Guide for Programme Managers. Geneva: UNICEF/UNU/WHO.

23. Erhardt JG, Estes JE, Pfeiffer CM, Biesalski HK, Craft NE, 2004. Combined measurement of ferritin, soluble transferrin receptor, retinol binding protein, and C-reactive protein by an inexpensive, sensitive, and simple sandwich enzyme-linked immunosorbent assay technique. J Nutr 134: 3127-3132.

24. Thurnham DI, McCabe LD, Haldar S, Wieringa FT, NorthropClewes CA, McCabe GP, 2010. Adjusting plasma ferritin concentrations to remove the effects of subclinical inflammation in the assessment of iron deficiency: a meta-analysis. Am J Clin Nutr 92: 546-555.

25. World Health Organization, Centers for Disease Control and Prevention, 2005. Assessing the Iron Status of Populations. Department of Nutrition for Health and Development, ed. Geneva: WHO/CDC

26. Grant FK, Suchdev PS, Flores-Ayala R, Cole CR, Ramakrishnan U, Ruth LJ, Martorell R, 2012. Correcting for inflammation changes estimates of iron deficiency among rural Kenyan preschool children. J Nutr 142: 105-111.

27. Beguin Y, 2003. Soluble transferrin receptor for the evaluation of erythropoiesis and iron status. Clin Chim Acta 329: 9-22.

28. World Health Organization, 1996. Indicators for Assessing Vitamin A Deficiency and Their Application in Monitoring and Evaluation Intervention Programmes. Geneva: WHO.

29. Chong SS, Boehm CD, Higgs DR, Cutting GR, 2000. Single-tube multiplex-PCR screen for common deletional determinants of alpha-thalassemia. Blood 95: 360-362.

30. Waterfall CM, Cobb BD, 2001. Single tube genotyping of sickle cell anemia using PCR-based SNP analysis. Nucleic Acids Res 29: E119.

31. Williams TN, Wambua S, Uyoga S, Macharia A, Mwacharo JK, Newton CR, Maitland K, 2005. Both heterozygous and homozygous alpha+ thalassemias protect against severe and fatal Plasmodium falciparum malaria on the coast of Kenya. Blood 106: 368-371.

32. Stothard P, 2000. The sequence manipulation suite: JavaScript programs for analyzing and formatting protein and DNA sequences. Biotechniques 28: 1102, 1104.

33. Zlotkin SH, Schauer C, Christofides A, Sharieff W, Tondeur MC, Hyder SM, 2005. Micronutrient sprinkles to control childhood anemia. PLoS Med 2: e1.

34. Filmer D, Pritchett LH, 2001. Estimating wealth effects without expenditure data-or tears: an application to educational enrollments in states of India. Demography 38: 115-132.

35. Victora CG, Adair L, Fall C, Hallal PC, Martorell R, Richter L, Sachdev HS; Maternal, Child Undernutrition Study G, 2008. Maternal and child undernutrition: consequences for adult health and human capital. Lancet 371: 340-357.

36. SAS Institute Inc, 2012. Sample Survey Design and Analysis. Available at: http://support.sas.com/rnd/app/da/new/dasurvey.html. Accessed March 15, 2012

37. Zack M, Singleton J, Wall K, Delaney K, 2011. Collinearity Diagnostics Using the Information Matrix. Cary, NC: SAS Institute.

38. George J, Yiannakis M, Main B, Devenish R, Anderson C, An US, Williams SM, Gibson RS, 2012. Genetic hemoglobin disorders, infection, and deficiencies of iron and vitamin a determine anemia in young Cambodian children. $J$ Nutr 142: 781-787.

39. Nyakeriga AM, Troye-Blomberg M, Mwacharo JK, Wambua S, Williams TN, 2005. Nutritional iron status in children with alpha+ thalassemia and the sickle cell trait in a malaria endemic area on the coast of Kenya. Haematologica 90: 552-554.

40. Rees DC, Williams TN, Maitland K, Clegg JB, Weatherall DJ, 1998. Alpha thalassemia is associated with increased soluble transferrin receptor levels. Br J Haematol 103: 365-369.

41. Suchdev PS, Ruth LJ, Woodruff BA, Mbakaya C, Mandava U, Flores-Ayala R, Jefferds ME, Quick R, 2012. Selling Sprinkles micronutrient powder reduces anemia, iron deficiency, 
and vitamin A deficiency in young children in western Kenya: a cluster-randomized controlled trial. Am J Clin Nutr 95: $1223-1230$

42. Zeba AN, Sorgho H, Rouamba N, Zongo I, Rouamba J, Guiguemde RT, Hamer DH, Mokhtar N, Ouedraogo JB, 2008. Major reduction of malaria morbidity with combined vitamin $\mathrm{A}$ and zinc supplementation in young children in Burkina Faso: a randomized double blind trial. Nutr J 7: 7

43. Sanjoaquin MA, Molyneux ME, 2009. Malaria and vitamin A deficiency in African children: a vicious circle? Malar J 8: 134

44. Kreuels B, Kobbe R, Adjei S, Kreuzberg C, von Reden C, Bater K, Klug S, Busch W, Adjei O, May J, 2008. Spatial variation of malaria incidence in young children from a geo- graphically homogeneous area with high endemicity. J Infect Dis 197: 85-93.

45. Kreuels B, Kreuzberg C, Kobbe R, Ayim-Akonor M, ApiahThompson P, Thompson B, Ehmen C, Adjei S, Langefeld I, Adjei O, May J, 2010. Differing effects of $\mathrm{HbS}$ and $\mathrm{HbC}$ traits on uncomplicated falciparum malaria, anemia, and child growth. Blood 115: 4551-4558.

46. Wambua S, Mwacharo J, Uyoga S, Macharia A, Williams TN, 2006. Co-inheritance of alpha+-thalassemia and sickle trait results in specific effects on hematological parameters. $\mathrm{Br} J$ Haematol 133: 206-209.

47. Rogerson $\mathrm{S}, 2006$. What is the relationship between haptoglobin, malaria, and anemia? PLoS Med 3: e200. 